\title{
Observing copepods through a genomic lens
}

\author{
James E Bron ${ }^{1 *}$, Dagmar Frisch ${ }^{2}$, Erica Goetze ${ }^{3}$, Stewart C Johnson ${ }^{4}$, Carol Eunmi Lee ${ }^{5}$ and Grace A Wyngaard ${ }^{6}$
}

\begin{abstract}
Background: Copepods outnumber every other multicellular animal group. They are critical components of the world's freshwater and marine ecosystems, sensitive indicators of local and global climate change, key ecosystem service providers, parasites and predators of economically important aquatic animals and potential vectors of waterborne disease. Copepods sustain the world fisheries that nourish and support human populations. Although genomic tools have transformed many areas of biological and biomedical research, their power to elucidate aspects of the biology, behavior and ecology of copepods has only recently begun to be exploited.

Discussion: The extraordinary biological and ecological diversity of the subclass Copepoda provides both unique advantages for addressing key problems in aquatic systems and formidable challenges for developing a focused genomics strategy. This article provides an overview of genomic studies of copepods and discusses strategies for using genomics tools to address key questions at levels extending from individuals to ecosystems. Genomics can, for instance, help to decipher patterns of genome evolution such as those that occur during transitions from free living to symbiotic and parasitic lifestyles and can assist in the identification of genetic mechanisms and accompanying physiological changes associated with adaptation to new or physiologically challenging environments. The adaptive significance of the diversity in genome size and unique mechanisms of genome reorganization during development could similarly be explored. Genome-wide and EST studies of parasitic copepods of salmon and large EST studies of selected free-living copepods have demonstrated the potential utility of modern genomics approaches for the study of copepods and have generated resources such as EST libraries, shotgun genome sequences, BAC libraries, genome maps and inbred lines that will be invaluable in assisting further efforts to provide genomics tools for copepods.

Summary: Genomics research on copepods is needed to extend our exploration and characterization of their fundamental biological traits, so that we can better understand how copepods function and interact in diverse environments. Availability of large scale genomics resources will also open doors to a wide range of systems biology type studies that view the organism as the fundamental system in which to address key questions in ecology and evolution.
\end{abstract}

Keywords: genome organization, ecogenomics, parasitism and symbiosis, biological invasion, diapause, response to environmental change

\section{Background}

The copepods are an extremely ancient group, likely having diverged from other arthropod taxa between 388-522 million years ago [1]. They are also an extraordinarily diverse group with respect to their morphologies, physiologies, life-strategies and habitat preferences, with adult sizes ranging from $<0.1 \mathrm{~mm}-23 \mathrm{~cm}$. Genomics, defined as the study of genome structure and composition as well as the study of gene expression and

\footnotetext{
* Correspondence: jeb1@stir.ac.uk

${ }^{1}$ Institute of Aquaculture, University of Stirling, Stirling FK9 4LA, Scotland, UK Full list of author information is available at the end of the article
}

function (transcriptomics), has been underutilized in studies of copepods. Although over 12000 validated species of copepods have been recognised to date, there are only modest sequence resources for copepods in public databases. To date, sequencing efforts and the application of genomic techniques have been limited to a small number of species in the orders: Harpacticoida, Calanoida, Cyclopoida, and Siphonostomatoida with estimated species numbers of 7288, 4937, 3241 and 3348, respectively [2]. In this article we discuss why new investments in copepod genomic research are warranted and illustrate how the development of genomics
C Biomed Central

() 2011 Bron et al; licensee BioMed Central Ltd. This is an Open Access article distributed under the terms of the Creative Commons Attribution License (http://creativecommons.org/licenses/by/2.0), which permits unrestricted use, distribution, and reproduction in any medium, provided the original work is properly cited. 
resources for copepods will enable researchers to address key questions related to environmental and ecosystem health, the sustainability of fisheries, evolution, symbiosis and parasitism, biological invasion, and speciation.

\section{The global importance of copepods}

Copepods are more abundant than any other group of multicellular animals, including the hyper-abundant insects and nematodes [3]. They pervade the majority of natural and man-made aquatic systems, inhabiting a domain that extends from the nutrient-rich black oozes of abyssal ocean depths to the nutrient-poor waters of the highest mountain tarns. Swarms of copepods can reach densities of up to 92,000 individuals $\mathrm{L}^{-1}$ [4]. Some species have escaped traditional aquatic habitats, and live in rain forest canopies, leaf-litter, hot springs, between sand grains, in hyper-saline waters ( 200 ppt) and in caves, as well as in symbiotic associations with other animal and plant species. Deeply divergent morphologies are found in relation to free-living or parasitic lifestyles, with some groups appearing classically "arthropodan", and others unrecognizable as such (Figure 1).

As the dominant secondary producers of the sea, copepods are the linchpin of aquatic food-webs. They consume microorganisms and are preyed upon by higher trophic levels, including fish and whales. In particular, they serve as primary prey for early life history stages of many fish species of economic importance [5], such as cod, herring, anchovy, flounder, and salmon. Copepods contribute significantly to many marine and freshwater ecosystem services, which have an estimated value of 22.6 trillion USD per annum [6]. For example, fish provide more than 2.9 billion people with more than $15 \%$ of their daily animal protein, and fisheries generate a net export value of $\$ 24.6$ billion per annum for developing countries [FAO Newsroom (2006) http://www.fao.org/Newsroom/en/news/2006/ 1000301/index.html]. Copepods critically support this marine fish production, and therefore play an important role in the nutrition, health and well-being of people who have little access to other sources of animal protein. Through their vertical migrations between surface and deeper waters, copepods also play a major role in carbon transfer into the deep sea and thus to the global carbon budget (reviewed in [7]). Copepods are sensitive indicators of climate change, with warming ocean temperatures affecting copepod community structure, abundance, distribution and seasonal timing (e.g., [8]). In turn, changing copepod distributions have resulted in reduced recruitment and productivity of regional fisheries, such as the North Sea cod stocks (e.g. [5]).
Copepods harbor a wide range of human and fish pathogens. Pathogenic bacteria, such as Salmonella spp., Enterococcus faecalis, Aeromonas spp., and Arcobacter spp., as well as several pathogenic species of Vibrio, including Vibrio cholerae have been isolated from copepods [9-12], however, their role as vectors of waterborne bacterial pathogens of humans remains poorly understood.. Copepods are intermediate hosts for the Guinea worm, Dracunculus mediensis, which causes the debilitating disease dracunculiasis [13], as well as fish tapeworms (e.g. Diphyllobothrium latum) and anisakid nematodes that can also infect humans [14]. In addition to the status of copepods as carriers of pathogens, many parasitic and predatory copepods are in themselves pathogenic and have considerable impacts upon global freshwater and marine fisheries, with major economic consequences recognized primarily in aquaculture [15-17].

\section{Copepods: a resource for investigating fundamental biological processes}

The extraordinary diversity of forms and life-strategies of copepods makes them very suitable for studies of a variety of fundamental biological processes that are of broad interest to the scientific community. As yet, however, little has been elucidated concerning the genomic architectures, transcriptional profiles or mechanisms controlling transcription that drive and underpin this diversity. Copepods could be used to examine questions of how genomic architecture differs among taxa and whether this limits or drives the observed morphological and ecological divergence, thereby influencing speciation events [18]. A related question is whether apparent change or simplification of form or function is reflected in the genome. For example, what is the driving force in the adaptation of copepods to a parasitic mode? Do copepod parasites necessarily possess "degenerate" genomes or are transitions in lifestyle accomplished by both gene losses and gains, or more simply by changing patterns of transcription?

Similarly, genomic data can provide answers as to what phenotypic and genomic characteristics have enabled major habitat transitions in free-living species, such as the move from the benthos to the pelagic environment, or from marine to freshwater biomes. There are a wide range of examples in both free-living and symbiotic copepods of closely related species that show distinct niche breadths in both their distribution and tolerance to environmental conditions. What then, can genomic and transcriptional data tell us about organismal and population responses to the environment in these cases? Since tolerance of environmental change, or lack of it, is ultimately genome-driven, one might ask whether genomic studies on the physiological responses 


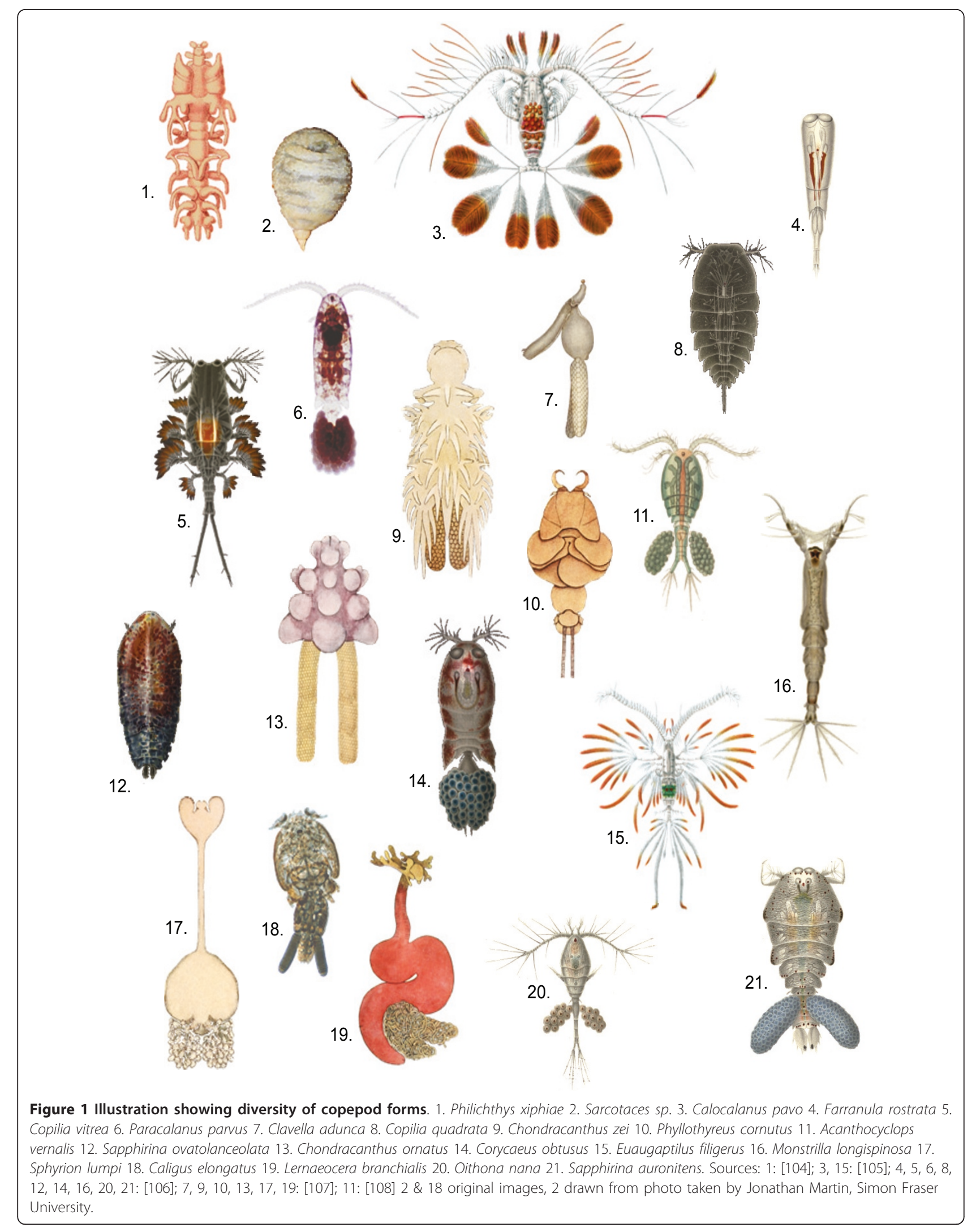


to stress, could also provide tools for monitoring or predicting organismal or population responses to climate change in terms of genome structure.

The broad size range of eukaryotic genomes has been long recognized, but its causes and biological significance are still debated [19]. Some copepod species possess a large range in genome size within individuals as a result of excision of large amounts of DNA from the presomatic cell lineage during development [20]. The streamlined somatic genomes and dramatically augmented germline genomes observed in such species may provide a useful study system for understanding genome organization and mechanisms for altering genome size.

The monophyly of some orders is doubted, and the number of orders is defined to be between eight and eleven [21]. Thus, it is difficult to confidently choose orders whose phylogenetic position is near the root of the copepod lineage when constructing phylogenetic hypotheses across the major arthropodan lineages. Phylogenetic studies are increasingly employing large data sets of nuclear protein or transcript sequences [22,23], to resolve relationships among major arthropodan and ecdysozoan lineages, but to date have not elucidated the phylogenetic position of copepods [22]. Improved resolution of relationships in the future may require the use of phylogenomic approaches that compare large portions of genome or transcriptome sequences. For these reasons it seems necessary to make investments in the provision of large scale genomic resources for several taxa, and the choice of these taxa should be informed by their phylogenetic position relative to other copepods.

Genomic studies of copepods are relevant to many areas of fundamental and applied research. In particular, knowledge of the mechanisms underlying host-parasite relationships and features such as drug resistance can help to increase the sustainability of wild and cultured fisheries through development of improved chemotherapeutants, vaccines, and integrated pest management strategies. Historically, much of the fundamental research on plankton composition, population dynamics and response to environmental factors was driven largely by the need to characterize the impact of plankton on fisheries. Until recently such work was undertaken in the absence of molecular tools, however, genomic technologies are now providing new kinds of information as well as substantially decreasing the time interval between sample collection and analysis.

Aspects of symbiosis and parasitism, biological invasion, diapause, and genome size and reorganization deserve special mention in the context of copepod genomics. We discuss these topics below, and provide examples of how genomic tools might be harnessed to study these problems.

\section{Discussion}

\section{Genomic insights into symbiosis and parasitism}

One of the most extraordinary aspects of copepods, and one of the features that makes them so interesting for a range of genomic, functional genetic and transcriptomic studies, is their astounding capacity to form associations with other organisms. Nearly half of all known copepod species live in such associations [24]. Boxshall [pers. comm.] estimated that $\sim 4152$ species from 109 families are symbiotic or parasitic and suggested that there have been 11 or more independent origins for symbiosis/parasitism within and across the various orders, with a minimum of seven independent colonization events in fish. These associations range from so-called micro-predation, where species opportunistically snatch meals from their associates, to fully endoparasitic relationships in which the parasite is completely enclosed within the host and intimately associated with it. These features make copepods particularly suitable for studies of the changes in genome structure, such as gene loss and gain, that accompany the transition to a parasitic lifestyle, especially in situations where the free-living ancestral forms and newly parasitic forms retain similar morphologies and still live within a constrained habitat e.g. Eucyclops bathanalicola inhabiting Lake Tanganyika, the only parasitic member of an otherwise free-living copepod clade [25]. The availability of free-living and closely related parasitic forms for genomic study may allow answering of questions on the need for pre-adaptations to facilitate the transition to symbiotic modes of existence and also questions of the existence of key stepping stone hosts/ associates in the multiple independent transitions to parasitism. Such questions are already being tackled in nematodes using genomic resources [26]. Development of novel functions, such as the ability to immuno-modulate or to stimulate hosts to directly support their survival, is also associated with the move to parasitism, as are the concomitant processes of speciation and adaptive radiation. Comparative genomic analysis and transcriptomic studies would allow a fuller exploration of the strategies by which copepod genomes evolve specializations to particular host-associations, as well as contribute to advancing our broader knowledge of parasite evolution. These types of studies have been conducted for other parasites, such as the causative agents of leishmaniasis (Leishmania spp.) and malaria (Plasmodium spp.) and have greatly contributed to understanding of their biology [27,28]. In another ecdysozoan, the filarial nematode Brugia malayi, genomic studies have indicated that up to $20 \%$ of predicted gene models are specific to the species and this has led to the suggestion that such genes may represent a pool 
of genes associated with defense/interaction with insect and human hosts [29].

Parasites have often been portrayed as degenerate versions of free-living forms, due to commonly observed features, such as morphological simplification. However, it has been suggested with respect to parasite genomes, that rather than being degenerate, they represent "...not the dustbins of history but the jewels of evolution" [30]. For example, while their ability to obtain a variety of resources from the host(s) may make some genomic features redundant, the relationship with the host is rarely one of passive nutrition, even for apparently morphologically simplified endoparasitic species such as Sarcotaces sp. (Figure 1 species 2). Kurland and colleagues [31] (pg 1013) suggest that "genome reduction and cellular simplification are hallmarks of parasites and symbionts", however, this may apply more to prokaryote and eukaryote intracellular parasites (e.g. see review by [32]) than to eukaryote ectoparasites and non-intracellular endoparasites. Copepod genome resources are thus far insufficiently developed to examine such questions, while genomic studies on ticks, which can similarly have longer term associations with hosts rather than taking quick meals, shows evidence for gene duplication and hence genome expansion. Like ticks, many copepod parasites are able to actively direct host physiology and have been shown, for example, to directly immunomodulate fish hosts [33] or cause associates to build costly structures that favor the parasite [34]. Such abilities require genomic and transcriptional adaptations that will be understood only when genomic resources to conduct inter- and intra-species comparisons are available. In ticks, duplication of genes within a given gene family may perform a number of functions including increasing expression levels of anti-host products, allowing targeting of multiple related host defensins or the same host molecule in multiple hosts, and providing antigenic variation to avoid host attack while affecting the same host target [35]. Gene duplication may also provide for differential function between parasite stages or states [35].

Many symbiotic/parasitic copepod groups have switched host phylum in the course of their evolutionary history [36], and the question of how such switches occur remains an important one, as it also informs wider questions of adaptive radiation and the nature of speciation. Monstrilloids (Figure 1 species 16) for instance, whose ancestral adult forms are considered to have been ectoparasites of fishes, are now known to display a free-living adult and a fully endoparasitic invertebrate-associated larval stage. In addition to the radical host switch, the group has also undergone major changes in functional morphology and life-history strategy, such that Huys et al. [36] (page 376) consider this combination of adaptations to be "probably unique in metazoan parasites". Because of their many and taxonomically varied associations, copepods lend themselves to the study of horizontal gene transfer between microbial host-associates and the copepod, as occurs in plant, fungal and animal nematodes [37] and between hosts and copepod symbionts, a relatively little explored area. Complete copepod genome sequences would provide a key resource for such studies, enabling the inference of gene trees to employ phylogenetic incongruence as a criterion for detecting horizontal gene transfer (e.g. [38]).

One of the most interesting correlates with the transition to a wholly parasitic state is the change in body morphology. While some ectoparasitic adult stages closely resemble their free-living counterparts, many mesoparasitic/endoparasitic groups undergo an extravagant metamorphosis from the juvenile to the adult stage that renders them almost unrecognizable as arthropods (e.g. Figure 1 species 2). Genomic analysis could help us understand these changes by uncovering patterns of gene expression and regulation that occur at individual stages during development and metamorphosis and that result in these radically different adult morphologies.

Parasitic copepods also have major impacts on wild and cultured fisheries. As an example, caligid copepods (sea lice) are responsible for disease-related economic losses to marine salmoniculture that exceed $\$ 430$ million worldwide per annum [17]. Sea lice have also been suggested to be directly or indirectly responsible for declines in wild salmonids. The control of parasitic copepods in aquaculture can involve the use of chemotherapeutants and as a result, some populations have developed resistance to treatment, a situation mirroring that observed in insect pests and perhaps unique among aquatic arthropods. Functional genetic studies are already providing insights into the basis for drug resistance in copepods (e.g. [39]) and into the mechanisms that copepods employ to avoid host immune responses (e.g. [33]). These observations increase the prospect of improved control of parasites in finfish culture systems. Gene knock-down studies in Lepeophtheirus using RNAi provide a powerful tool [40] to understand the function of individual genes, with attendant prospects for novel control strategies including development of vaccines or new chemotherapeutants. Functional genetic and transcriptomic studies also offer tools for monitoring the development of drug resistance in treated populations that are more sensitive and consistent than existing bioassays. Instead of measuring death or debilitation as outcomes of treatment, such tools allow measurement of direct or indirect response markers with a continuous distribution. New high throughput sequencing technologies which allow rapid simultaneous sequencing of 
millions of transcript or genome fragments per run [41] can similarly offer opportunities for detecting genomic markers for important traits such as drug resistance, which may then be used to develop parasite control strategies. Furthermore, genomics offers a powerful and innovative way to support the development of new therapeutants, as well as to identify novel compounds, such as immunomodulators, produced by parasitic copepods that are of scientific and/or medical importance. Identification of parasitic copepod orthologues of genes that are targets of therapeutants in other animals, especially those that are sufficiently different from that of their hosts, will help to identify and prioritize alternative therapeutants.

\section{Genetic mechanisms underlying biological invasions}

Invasive species pose major threats to biodiversity, ecosystem integrity, agriculture, fisheries, and public health, with economic costs of nearly $\$ 120$ billion per year in the US alone [42]. Understanding factors that allow some species to invade is crucial for mitigating and managing environmental impacts. Recent studies show that many invaders are crossing biogeographical boundaries into new habitats, and that evolutionary responses are often critical for these successful invasions [43-45]. Copepod invasions are a common and global phenomenon, the implications of which are poorly understood. Copepods generally comprise the most abundant and diverse taxonomic group within ship ballast water, and are thus transported worldwide in extremely large numbers [46]. Given the high number of pathogenic species found associated with copepods [9-14], copepod invasions could have important implications for dissemination and transmission of pathogens.

Invasive copepods provide particularly valuable models for exploring fundamental mechanisms of niche evolution. Frequent habitat shifts and short generation times make copepods amenable for analyzing the evolutionary and physiological mechanisms that underlie radical habitat transitions. As copepods are small and many species could be reared in the laboratory for several generations, they could be used for quantitative genetics and selection experiments, as well as association studies, to understand patterns of trait evolution and association between genes and traits. For example, within the past century the copepod Eurytemora affinis has invaded freshwater habitats from saline sources multiple times independently throughout the Northern Hemisphere [47]. Common-garden experiments have shown that these invasions have been accompanied by evolutionary changes in physiological tolerance, performance, and plasticity [48-50]. Most notably, freshwater populations have experienced evolutionary shifts in ion transport mechanisms, including increased activity and expression of the ion uptake enzyme V-type $\mathrm{H}^{+}$ATPase [50]. Modifying salinity alone during laboratory selection experiments recapitulated the evolutionary shifts in $\mathrm{V}$-type $\mathrm{H}^{+}$ ATPase activity observed in nature, providing strong support that salinity is a factor imposing selection in the wild [50]. Moreover, parallel evolutionary shifts were found in ion-motive enzyme activity and expression ( $\mathrm{V}$ type $\mathrm{H}^{+}$ATPase, $\mathrm{Na}^{+} / \mathrm{K}^{+}$-ATPase) across independent invasions [50]. In addition, a study using cDNA microarrays revealed parallel evolutionary shifts in expression of multiple genes and gene classes, including cuticle proteins, chaperones, cytoskeletal proteins, and ribosomal proteins, during independent invasions into freshwater habitats [50]. The parallel shifts suggest that shared genetic mechanisms might be implicated during these repeated evolutionary events.

As certain copepod species can be crossed in the laboratory, hybrid crosses between inbred lines, in conjunction with high-throughput sequencing, could be used to help determine whether evolutionary shifts in gene expression are the result of cis- or trans-regulatory changes in expression $[51,52]$. Such insights could provide invaluable information on the specific targets of selection and the causal mutations underlying evolutionary shifts in gene expression during independent invasion events. The latter would provide insights into the degree to which evolutionary pathways are labile or constrained during invasions. Moreover, as selection acts most strongly on genes underlying functionally important traits, identifying the genomic targets of natural selection during habitat invasions could reveal the traits that are critical for habitat shifts and address core questions regarding mechanisms of niche evolution. This general approach could also be profitably applied to understand other major habitat transitions within the Copepoda.

\section{Resurrection ecology and genetic regulation of diapause}

Diapause is a life history trait common to many marine and freshwater free-living copepod species and is shared with many other arthropod groups. Duration of diapause varies from only a few months in juveniles of cyclopoid species to centuries in calanoid eggs. The biological significance of long-lived diapause eggs ( $>300 \mathrm{yrs}$ in some species; [53]), however, remains to be established. The deposition of diapause eggs in lacustrine and coastal marine sediments provides unique access to genetic archives of past populations representative of historic genotypes. The field of resurrection ecology, which has focused, to date, on the water flea Daphnia (e.g. [54]) has the potential to significantly advance our understanding of evolutionary responses to local conditions, through the study of genetic adaptations to environmental change. These eggs are an important resource from 
which we can directly observe fitness traits of animals adapted to past environmental conditions $[55,56]$.

Although seasonal and environmental diapause patterns have been described for numerous copepod species [57], the suites of genes that are involved in diapause remain largely unexplored. In a number of arthropods, genes from the family of heat shock proteins are upregulated during diapause, acting as chaperone molecules against environmental stressors, e.g. temperature and anoxic conditions occurring during diapause [58-61]. In copepods, however, only one attempt has been made to employ genomic-related techniques to study diapause. Tarrant et al. [62] applied suppression subtractive hybridization gene libraries (SSH) and quantitative PCR (qPCR) to characterize gene expression in active and diapausing populations of Calanus finmarchicus, in order to describe the physiological regulation of dormancy. Using these techniques the authors were able to identify genes that were differentially expressed in these populations, including several that are involved in lipid synthesis leading up to dormancy and the chelation of metals during diapause. Identification of such genes is an important first step in the understanding of regulation and timing of diapause. The diapause trait itself is strongly dependent upon environmental cues such as temperature and/or photoperiod [57] and thus could be especially impacted by climate change. The significance of the genomic regulation and timing of diapause to a key group of organisms in the aquatic food web, is indisputable. This is particularly the case given the possible dramatic consequences of shifts in the timing of copepod diapause. Such shifts affect fish prey availability and recruitment (match-mismatch hypothesis [63]), and have critical downstream impacts on major coastal fisheries in marine systems.

\section{Genome size, reorganization, and co-adaptation}

The dynamic nature of genomes is becoming increasingly evident in copepods and other eukaryotes and is challenging established views of how genomes evolve [64]. Large differences in genome content over the course of the organismal life cycle, reshuffled gene arrangements in the mitochondria, and the role of coadaptation between nuclear and mitochondrial genomes during speciation events are areas where the molecular details of genome processes could be informed using genomic tools.

Embryonic chromatin diminution, the selective excision of large amounts of heterochromatic DNA from presomatic cell lineages, provides a dramatic example of augmentation of the germline genome and raises questions regarding the source of the increased amount of DNA and its relevance to the biology of the organism. For example, in Mesocyclops edax the somatic and germline nuclear DNA contents are $~ 3$ and $30 \mathrm{~Gb}$, respectively, while in Cyclops kolensis the DNA contents are $\sim 1$ and $75 \mathrm{pg}$, respectively $[20,65]$. The first studies to characterize the sequence identity of these streamlined somatic and "obese" germline genomes suggested preferential elimination of some microsatellite sequences and the DNA fragments located between microsatellites (e.g. $[66,67])$. Wyngaard and colleagues [20] posed two alternative mechanisms to account for the augmented germline genomes: (1) repetitive endocycles (repeated cycles of endonuclear DNA replication without intervening mitoses), and (2) proliferation of genetic elements in the germline genome. Data supporting the endocycle hypothesis are gleaned from thymidine labelling studies that reveal synthesis of DNA without intervening mitoses in $M$. edax germline nuclei containing 9-30 Gb $[65,68]$. The alternative explanation hypothesizes the proliferation of genetic elements, which is plausible based on the population biology of genetic elements and their influence on genome architecture [69] and the contribution of transposable elements to variation in genome size among closely related taxa [70]. Chromatin diminution may serve to remove selfish genetic elements that have proliferated in the germline genome before their deleterious effects can impact the somatic genome. Such a scenario has been posed for ciliates that possess a similar form of chromatin elimination [71]. Ciliates, some parasitic nematodes, and Japanese hagfish all possess chromatin diminution, although certainly not of the same type and origin as described in copepods [72]. Of the taxa possessing chromatin diminution, the population biology and ecology are well known only for the copepods, enhancing the likelihood that any fitness consequences of chromatin diminution are more likely to be elucidated in this group. These genomic modifications are only one of a large array of models of genome size augmentation prevalent in other eukaryotes, can have far-reaching consequences on genome architecture and evolution, and warrant attention [64]

Another example of genome reorganization among copepods concerns the variable order of genes in the mitochondrial genome, a trait that is often conserved among vertebrate groups. Although complete mitochondrial DNA sequences are only available from five copepod genera, existing data show that copepod mitochondrial genomes have large-scale gene rearrangements relative to each other as well as to the "typical" arthropod mitochondrial genome [73-75]. For example, in Tigriopus all genes are encoded on the same DNA strand. In four other studied species, however, two for which the full mitochondrial genome sequence is known (Lepeophtheirus salmonis and Calanus sinicus) and two for which only partial mitochondrial sequences are available (Eucalanus bungii and Neocalanus cristatus), both 
DNA strands contain coding regions $[74,76]$. Since these rearrangements result in the need for multiple promoter sites, studies of mtDNA gene expression in these different groups may provide new insights into how gene arrangements impact mitochondrial function.

Copepods have also served as model systems for understanding genomic co-adaptation. When gene flow among populations is restricted, natural selection can result in adaptation to local environments. Selection also acts within the genome to retain sets of alleles that interact well and produce the fittest individuals (regardless of external environment), a process known as genomic co-adaptation [77]. When divergent populations are hybridized, breakdown of co-adaptation is manifest in poor hybrid fitness, often viewed as a first step in the formation of new species. The tidepool copepod Tigriopus californicus has become a model system for studies of co-adaptation and hybrid breakdown. Ellison and Burton [78] found that hybridization leads to altered transcription and replication of $T$. californicus mtDNA, a consequence of disrupted co-adaptation between nuclear and mitochondrial genomes. Edmands et al. [79] found evidence for maladaptive combinations of alleles within natural $T$. californicus populations, presumably due to fixation of deleterious mutations by genetic drift in small populations. Most recently, protein-coding regions (the transcriptome) of two divergent populations of $T$. californicus, obtained using 454 pryosequencing, revealed evidence of positive selection that potentially plays a role during the early stages of reproductive isolation [18]. Genome-level studies of hybrid individuals promise to elucidate the genetic interactions that underlie hybrid breakdown and may provide clues to the process of speciation. Similar conclusions about the role of selection in the formation of hybrids were gleaned from the first nearly complete map of a copepod genome derived from hybrids between two T. californicus populations [80].

\section{Using genomic tools to detect responses to the environment}

Understanding responses of copepods to environmental conditions is one important research focus that has been limited by available techniques. To date, relatively few research groups have used genomics-related technologies to study zooplankton responses to their environment. However, recent insights from the genome of the freshwater cladoceran Daphnia pulex suggest that gene duplication and differential expression can be an important avenue enabling flexible phenotypic responses to ecological challenges [81]. Despite possessing a diminutive genome of about $200 \mathrm{MB}$, the estimated number of genes of this zooplankter is over 30,000, about 10,000 more than that found in humans. More than a third of these genes have no known homolog. The elevated gene count in $D$. pulex has been attributed to gene duplication and retention, which have allowed distinct expression patterns to evolve across paralogs. Known for its morphological and physiological plasticity in responding to environmental insults (e.g. heavy metals) and ecological conditions (e.g. predation), Daphnia has been used as a model for both toxicological and ecological studies (e.g., for the Environmental Protection Agency; [82]). The eco-responsive genome of Daphnia provides a vision of the nature and extent of the insights that might be obtained from comparable studies of copepod genomes. Because copepods have greater taxonomic, life history, and habitat diversity, it may be possible to obtain insights into how genome architecture and expression patterns facilitate biological response across a wider range of environmental conditions. In addition, copepods lack parthenogenesis and thus may provide a more appropriate model for other obligate sexually reproducing organisms.

Within copepods, the majority of studies conducted using genetic and genomic technologies to study responses to environmental conditions have been in toxicology. The ability to detect copepod responses to environmental pollutants has been limited by a lack of specific assays for most traits of interest, and has necessarily focused on responses at the individual or population level. The use of genomics-related technologies has several advantages over traditional methods, which often rely on whole-animal assays and endpoint measurements such as time to death, and allows for the identification of molecular pathways involved in any given response and enables monitoring of sub-lethal effects at the genetic level. Recent examples of work in this area include candidate gene studies on the effects of trace metals in Tigriopus japonicus [83], and the effect of oil exposure on gene expression in Calanus finmarchicus [84]. Hansen et al.'s [84] work on C. finmarchicus is particularly timely in light of the large volumes of crude oil spilled in the Gulf of Mexico in 2010. This study demonstrated that levels of glutathione S-transferase (GST) and cytochrome P-450 330A1 (CYP330A1) changed significantly in response to the presence of dispersed petrogenic oil in seawater, with differential responses being observed in copepod lipid levels/reproductive state. Recently there has been a transition in copepod studies, from the use of single genes to investigate traits of interest to the use of large-scale transcriptional profiling. Large-scale transcriptional profiling provides the capability to simultaneously assess the involvement of thousands of genes in a particular biological process, allowing new pathways, mechanisms of control, and relationships between different genes to be discovered. Examples of such an approach are the use of 
microarrays in trace metal risk assessment using $T$. japonicus [85] and the use of subtractive hybridization (SSH) to investigate effects of oil pollution on C. finmarchicus [86].

In marine ecology, genomics-related technologies could facilitate research to detect copepod responses to environmental change at the levels of genes, whole organisms and populations. One important contribution of genomics could be the development of molecular markers for physiological stressors, such as starvation, infection (parasitic, bacterial, viral), senescence, and thermal stress (climatic change), which could provide insight into how these processes influence growth and mortality in natural populations. Studies that document the frequency, extent, and sensitivities of copepods to stress from a variety of sources would provide important insights into the proximate causes of seasonal changes in population abundance and the factors that limit biogeographic range, and could also prove useful in predicting population responses to climate change (e.g., population forcing through thermal stress). Recently, several laboratories have started to develop techniques to investigate copepod gene expression in order to better understand stress in response to environmental conditions. Voznesensky et al. [87] used a qPCR approach to quantify expression levels of hsp70 in response to thermal stress in the abundant North Atlantic copepod, C. finmarchicus, and found that increases in gene expression due to migration or transport across natural thermal gradients should be detectable in assays of field populations. More recently, Tarrant et al. [62], among others, have used gene expression studies to begin identifying genes that are regulated seasonally. Finally, Christie et al. [88] have generated approximately 10,000 expressed sequence tags (ESTs: Table 1) and developed a 1000-probe microarray for Calanus finmarchicus that is being used to study gene expression patterns associated with season and location under natural as well as experimental conditions.

Genomics-related technologies could also be used to assess shifts in copepod community composition or biogeographic range in response to environmental conditions. Determination of the composition of bulk zooplankton samples using traditional methods is a time consuming process that requires broad expertise in taxonomy to ensure correct species identification. Community metagenetics and DNA barcoding provide a high throughput alternative to visual assessment of the diversity of plankton assemblages, with more conventional genetic approaches typically used to identify eggs and larval stages, to detect cryptic species, and to study species distributions (e.g. [89-91]). Although metagenomic approaches (see [92] for a lucid commentary) are now being used to assess diversity of aquatic microbial communities (e.g. [93]), their application to copepods and other metazoans may be limited due to the larger genome size and complexity of eukaryotes. However, the metagenetic approach of high throughput sequencing of biodiversity tags (e.g., hypervariable regions of ribosomal genes) to assess diversity of protistan assemblages (e.g.,

Table 1 Publicly available sequence data for copepods

\begin{tabular}{|c|c|c|c|c|c|}
\hline & $\begin{array}{l}\text { Core } \\
\text { nucleotide }\end{array}$ & $\begin{array}{l}\text { Expressed } \\
\text { sequence } \\
\text { tags }\end{array}$ & $\begin{array}{l}\text { Mitochondrial } \\
\text { genome } \\
\text { sequence }\end{array}$ & $\begin{array}{l}\text { Nuclear genomic sequence } \\
\text { (chromosome/whole } \\
\text { genome) }\end{array}$ & Scientific relevance of species \\
\hline $\begin{array}{l}\text { Hexapoda } \\
\text { (insects) }\end{array}$ & $3,076,212$ & $4,496,444$ & 235 & $51 / 20$ & \\
\hline $\begin{array}{l}\text { Copepoda } \\
\text { (Total) }\end{array}$ & 15,316 & 207,282 & 8 & $0 / 0$ & \\
\hline $\begin{array}{l}\text { Lepeophtheirus } \\
\text { salmonis }\end{array}$ & 4,345 & 129,250 & 2 & $0 / 0$ & $\begin{array}{l}\text { Parasite of wild and farmed marine fish, } \\
\text { economically and ecologically important }\end{array}$ \\
\hline $\begin{array}{l}\text { Caligus } \\
\text { rogercresseyi }\end{array}$ & 1,610 & 32,037 & 0 & $0 / 0$ & $\begin{array}{l}\text { Parasite of wild and farmed marine fish, } \\
\text { economically important }\end{array}$ \\
\hline $\begin{array}{l}\text { Caligus } \\
\text { clemensi }\end{array}$ & 1,227 & 14,806 & 0 & $0 / 0$ & Parasite of wild and farmed marine fish \\
\hline $\begin{array}{l}\text { Lernaeocera } \\
\text { branchialis }\end{array}$ & 1 & 14,927 & 0 & $0 / 0$ & Parasite of wild marine fish \\
\hline $\begin{array}{l}\text { Calanus } \\
\text { finmarchicus }\end{array}$ & 48 & 11,461 & 0 & $0 / 0$ & Key marine zooplankton species \\
\hline $\begin{array}{l}\text { Tigriopus } \\
\text { californicus }\end{array}$ & 920 & 4,801 & 3 & $0 / 0$ & $\begin{array}{l}\text { Tidepool copepod used as a model system in } \\
\text { evolutionary genetics and ecotoxicological } \\
\text { research }\end{array}$ \\
\hline
\end{tabular}

Publicly available sequence data for copepods and for insects, the other hyper-abundant arthropod taxon, which have received far more attention in genomics studies (source: Taxonomy Browser, GenBank release 184.0, accessed July 22nd, 2011). Data include only those copepod species for which there are greater than 1000 core nucleotide or EST sequences. While data resulting from shotgun genome sequencing exist for L. salmonis ( 475,815 sequences) no complete genome assembly has thus far been conducted. 
[94]) is promising, and a similar approach could be developed for metazoan zooplankton based on the DNA barcoding gene mtCOI (mitochondrial cytochrome oxidase I). Use of high-throughput sequencing technologies could revolutionize plankton identification and the assessment of ecosystem health by allowing comprehensive and rapid surveys of plankton community composition.

\section{Resources and strategies}

\section{Existing copepod sequence resources}

Currently no assembled genomes exist for the Copepoda, although some limited shotgun sequencing of the genome of the salmon parasite Lepeophtheirus salmonis has been undertaken recently. Thus, with the exception of 8 mitochondrial genome sequences, the publicly available genomics resources for copepods consist primarily of expressed sequence tags (EST's) that have been obtained from normalized, non-normalized or subtracted libraries. Of these, the largest numbers have been obtained for the parasitic species L. salmonis and Caligus rogercresseyi. These species have received attention due to their economic importance to salmon farming. Although many of these data were initially generated to support specific projects related to their control and treatment, they have enabled a wide range of studies on ecology [95], development [96], drug resistance [39] host-pathogen interactions [33] and the characterization of gene families of interest [97]. The second largest number of sequences belongs to the key free-living planktonic calanoid species C. finmarchicus. These genomic resources have facilitated the development of cDNA and oligo-based microarrays for L. salmonis and C. finmarchicus that are being utilized to investigate a variety of aspects of their biology, such as their hostinteractions [96], and responses of planktonic species to environmental changes associated with season or depth [88]. These resources have also provided the building blocks for techniques that are fundamental to deeper understanding of gene function, such as individual gene knock-out through RNA interference [40].

When compared to other arthropod groups such as the insects, available genomics resources for copepods are extremely limited, especially given the dominance and importance of this group in aquatic ecosystems (Table 1). Currently, the most extensive arthropod genomic resources are those developed for the fruit fly Drosophila melanogaster and other Drosophila spp. Genome sequencing and assembly and consequent downstream genomic studies have revolutionized genomic studies in this species and have, moreover, proven highly informative with respect to other metazoans including humans. A précis of the enormous advantages that genome resources have provided for the Drosophila research community is provided by Ashburner et al. [98] and current work seeks, among other tasks, to expand on this knowledge by providing a comprehensive identification of the sequence-based functional elements within the $D$. melanogaster genome as part of the model organism Encyclopedia of DNA Elements (modENCODE) project [99]. Recent sequencing of other arthropods, including mosquito disease vectors (e.g. [100]) and other insects with high economic/environmental importance, e.g., honey bees [101], have also advanced genomic and biological studies in these species. Genomes of aquatic arthropods are limited to those of Daphnia spp. [81], which like copepods, bring to the table an extensive history of biological, behavioral and ecological research that considerably widens the benefits, in terms of relating genome structure to environmental forces and biological function, that may be obtained from provision of genomics resources.

\section{Why adopt copepods as genomic models?}

It is clear from the above discussions that copepods can be used to address many fundamental and applied biological problems. While this might be true of many groups, the ubiquity, importance, and diversity of copepods, allied with their suitability for laboratory studies, makes them potentially highly informative as model organisms across a wide range of research disciplines. Their utility, however, is dependent upon the generation and availability of suitable genomics resources.

The two dominant invertebrate genetic model organisms, the nematode C. elegans and fruit fly Drosophila, are members of other hyper-abundant and hyper-diverse clades, leaving the copepods as the only hyper-diverse ecdysozoan group, for which a full or draft genome assembly does not exist. Furthermore, the only crustacean genomes sequenced and assembled to date are those of the branchiopods Daphnia pulex and D. magna so that the diverse crustacean clade itself is highly under-represented in terms of genome models (Figure 2). Daphnia was listed as the 13th official model organism for biomedical research by the National Institutes of Health, and the diverse Copepoda harbor many species that will similarly prove highly informative to biomedical research.

\section{Criteria for candidates for large-scale resources}

Selection of candidate species for whole-genome sequencing is complicated by the considerable genetic diversity among orders, as well as within single species or species complexes (e.g., [102]). Such high divergence emphasizes the need to target several copepod species in parallel for the development of genomics resources. Still, for many taxa, the key criteria typically used for choosing such candidate species [58] are lacking. The haploid genome size of copepods http://www.genomesize.com covers a broad range, from $0.14 \mathrm{pg}-12.46 \mathrm{pg}$ 


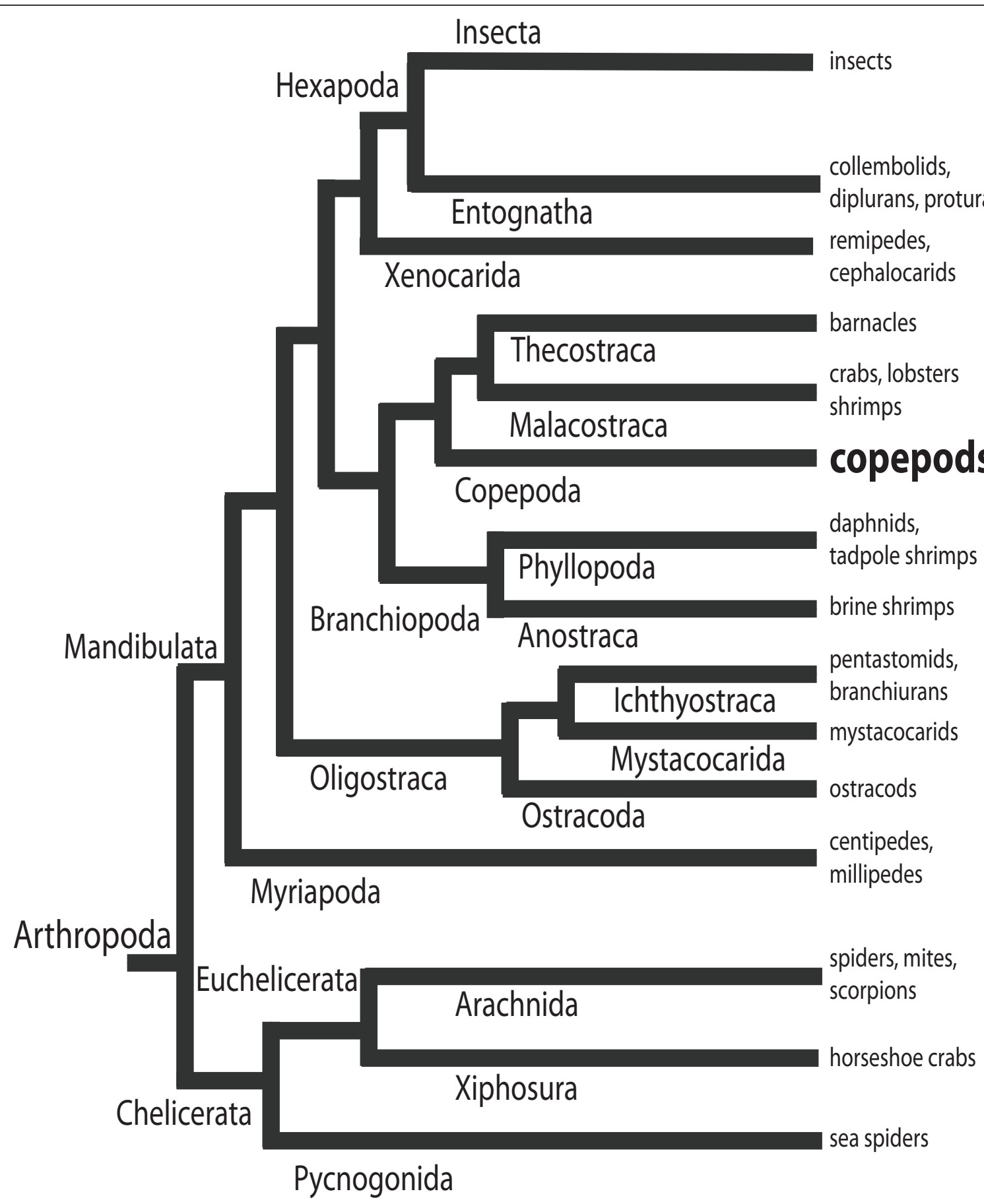

Figure 2 Simplified phylogram showing the position of the copepods with respect to the other major arthropod taxa. This topology is based on the largest data set available, $41 \mathrm{~Kb}$ of single-copy nuclear protein coding genes, and is modified after [1].

(compared to a human $=3.5 \mathrm{pg}$ ) and clearly, with other factors being equal, the smaller the genome, the more rapid and inexpensive the sequencing and assembly. Choosing species that possess a conventional genetic system will also increase the likelihood that sequencing and assembly of the genome is straight-forward. Widely distributed species ease access to local populations for researchers who collectively bring a broad array of interests and expertise to the field. Many species are already routinely cultured (e.g. Temora longicornis, Eurytemora affinis, Centropages hamatus, Tigriopus californicus, $T$. japonicus, Tisbe biminiensis, Acartia tonsa, Mesocyclops 
longisetus, Lepeophtheirus salmonis) although the parasitic species still require live hosts for culture. A number of inbred lines of copepods already exist (e.g. E. affinis, L. salmonis and T. californicus), which should be helpful in assisting genome assembly, promoting experimental consistency and helping dissection of particular traits such as chemotherapeutant resistance or salinity tolerance. Although molecular and computational techniques have allowed considerable progress to be made in the resolution of phylogenetic relationships among major ecdysozoan lineages (e.g. [22]), the complete absence of higher-order molecular phylogenies for the Copepoda impedes the choice of candidate species based on phylogenetic position. Perhaps, therefore, the choice of candidate species is best determined by the relative merits of the particular biological problems these candidates would address.

Genomic resources exist for species in the Harpacticoida, Siphonostomatoida, and Calanoida (see Table 1). Affordable and efficient comparative genomics, utilizing several copepod taxa and a combination of whole genome and EST analysis, is now feasible due to recent advances in sequencing technology. The concomitant decline in sequencing costs will likely alter the relative amounts of genomic data available to design efficient and successful sequencing projects for a particular species. Thus, any priority list of candidate species for large scale genomics studies is a moving target. If the goal is to understand the diversity of form and function in copepods, the evolutionary mechanisms responsible for them, and how this diversity is related to other major arthropod groups, it is clear that forms representing the diverse orders will require study. Similarly, if the goal is to understand symbiosis and parasitism, pairs of sister taxa that include free-living and parasitic forms will have to be compared. Alternatively, if the goal is to the reveal the genetic mechanisms involved in population differentiation and speciation, a single species such as $T$. californicus or E. affinis may suffice. It is more likely that suites of copepod species will be required for robust tests of most problems of general interest, whether the questions are fundamental or applied or whether they are ecological or evolutionary. The principal goal in the ongoing development of genomic resources for copepods should be the targeting of a diversity of species such that genomic resources facilitate research on diverse problems of global importance.

\section{Sequencing Goals}

In considering a whole genome sequencing project the advantages of a high coverage sequencing effort with subsequent assembly over low coverage/transcriptome sequencing effort need to be assessed. Assembly of the millions of short sequences provided by low cost sequencing is facilitated by availability of a pre-existing reference genome. In copepods, we do not yet know which species might be representative (ancestral), nor do we know the extent of differences in genomic structure, gene order, repeats and other features of the genome, which might be relevant to sequence assembly. The current pace of technological change precludes a discussion of sequencing strategy in this paper. However, a number of questions regarding sequencing of copepods might still be constructively addressed.

A genome does not need to be sequenced in depth and assembled to be useful (even the human genome remains incomplete). The level of coverage and contiguity required depends in part upon whether the objective is to examine a single species, a number of closely related species or an array of diverse forms. Furthermore, whether the purpose of the study is structural or functional genomics will have a bearing on the sequencing approach. Although whole genome sequencing has been the most rigorous method of choice for identifying SNPs (single nucleotide polymorphisms) when dissecting the origin and population structuring of traits of interest, the low cost RAD-Seq method (restriction-site-associated DNA sequencing) may prove to be just as informative [103]. Whole genome sequencing may still be the method of choice, however, for identifying other structures such as repeats and indels.

The power of a highly assembled genome is that it can potentially provide a framework for the rapid assembly of genomes from the same or closely related species and more importantly, a reference for subsequent studies involving high throughput sequencing that provide high numbers of short reads. It is extremely likely that the divergence among copepod lineages is so great that a full genome sequence of one copepod species will not suffice as a scaffold for assembly of others, save for quite closely related species.

\section{Summary}

Copepods comprise an extremely abundant, diverse and ecologically significant group, for which few studies have fully exploited the power of genomic technologies. Provision of multiple genomes or large-scale resources for a number of species could provide unparalleled insights into biodiversity and evolution. This single taxon has evolved into a diverse group with multiple convergent instances of the evolution of parasitic associations, a transition from benthic to pelagic life-styles, and invasions into extreme habitats (deep ocean, caverns, polar regions). Even the sequencing of a single copepod genome would provide a basis for evolutionary comparisons, such as resolving relationships among major pancrustacean taxa. Availability of large scale genomic resources also opens the door to a wide range of other "omics" studies. In addition, such resources will: 1) 
allow research groups that have limited resources to begin applying molecular methods in their research, 2) greatly extend the number of traits we can study to better understand copepod biology and interactions with their environment, 3) enable researchers to develop tools to address many questions where more traditional methods have limitations, 4) enable development of standardized molecular techniques, providing a measure of uniformity and consistency to the measurement of biological properties of copepods, and 5) attract new researchers from diverse disciplines into the field. Development of copepod genomics resources must be supported by the education of present and future generations of scientists in genomics and bioinformatics, in order to ensure successful exploitation of these tools and resources. Current strategies must anticipate stepchanges in approach, as well as providing resources to carry out further types of 'omics' studies on copepods.

\author{
Acknowledgements \\ The ideas in this article were generated, in part, through discussions among \\ participants at the Copepod Genomics Workshop (see http://www. \\ monoculus.org/ for white paper) held during the World Association of \\ Copepodologists Conference in Pattaya, Thailand, July 2008. We thank the \\ numerous others who offered ideas and/or made improvements on the \\ manuscript, especially Jeffrey Boore, Geoff Boxshall, Ronald Burton, Rita \\ Colwell, Joana Carneiro Da Silva, Björn Hansen and Petra Lenz. The \\ workshop was funded by the World Association of Copepodologists and \\ NSF grant DEB 0820866 to GAW.
}

\section{Author details \\ 'Institute of Aquaculture, University of Stirling, Stirling FK9 4LA, Scotland, UK. 2University of Oklahoma Biological Station, Kingston, OK 73439, USA. ${ }^{3}$ Department of Oceanography, School of Ocean and Earth Science and Technology, University of Hawaii at Manoa, Honolulu, Hawaii 96822, USA. ${ }^{4}$ Fisheries and Oceans Canada, Pacific Biological Station, Nanaimo, BC, V9T 6N7, Canada. ${ }^{5}$ Center of Rapid Evolution (CORE), University of Wisconsin, Madison, WI, USA. ${ }^{6}$ Department of Biology, James Madison University, Harrisonburg, VA, 22807, USA.}

\section{Authors' contributions}

All authors contributed ideas during the Copepod Genomics Workshop held during the World Association of Copepodologists conference in Thailand 2008. JEB, DF, SCJ and GAW drafted the manuscript. JEB prepared the table and figures. All authors intensively revised subsequent drafts of the manuscript and read and approved its final version.

\section{Authors' information}

James Bron is a marine biologist working in the area of cultured fish health and welfare and has particular expertise in host-parasite interactions between salmonid fish and their copepod parasites. He also has longstanding experience in the application of genomic methods, particularly transcriptomic analysis. He is currently a senior lecturer in the Parasitology Research Laboratory, Institute of Aquaculture, University of Stirling, Scotland. Dagmar Frisch is an aquatic ecologist with special interest in the ecological genetics and the evolutionary ecology of crustacean zooplankton. She is a postdoctoral researcher at the University of Oklahoma Biological Station, USA.

Erica Goetze's areas of expertise cover the evolution and ecology of marine calanoid copepods, with her current research focused on understanding dispersal and gene flow in marine zooplankton populations. She is an assistant professor at the University of Hawaii at Manoa, Hawaii. Stewart Johnson's research areas include aquaculture, aquatic animal health and biotechnology/genomics with special interest in the development of genomics resources for key aquaculture species. He is Head of Aquatic Animal Health at Fisheries and Oceans Canada, Pacific Biological Station, Nanaimo, British Columbia.

Carol Lee is an evolutionary geneticist focusing on the quantitative genetics, population genetics, and genomics of invasive populations, including copepods. She is a professor in the Center of Rapid Evolution (CORE) and the Department of Zoology at University of Wisconsin, Madison. Grace Wyngaard's research focuses on copepod evolution, genome size, chromatin diminution and the phylogenetic relationship of copepods based on molecular and morphological characters. She is a professor in the Department of Biology at James Madison University, Virginia.

\section{Competing interests}

The authors declare that they have no competing interests.

Received: 8 February 2011 Accepted: 20 September 2011 Published: 20 September 2011

\section{References}

1. Regier J, Shultz J, Kambic R: Pancrustacean phylogeny: hexapods are terrestrial crustaceans and maxillopods are not monophyletic. Proceedings of the Royal Society of London, Biological Sciences 2005, 272:395-401.

2. Boxshall GIE: Neocopepoda. In World Copepoda database at Edited by: Walter TC, Boxshall G 2011 [http://www.marinespecies.org/copepoda/aphia. php? $\mathrm{p}=$ taxdetails\&id $=155876]$.

3. Humes A: How many copepods? In Ecology and Morphology of Copepods: Proceedings of the Fifth International Conference on Copepoda. Volume 292/ 293. Edited by: Ferrari FD, Bradley BP. London: Springer; 1994:1-7, Developments in Hydrobiology.

4. Buskey EJ, Peterson JO, Ambler JW: The swarming behavior of the copepod Dioithona oculata: In situ and laboratory studies. Limnology and Oceanography 1996, 41:513-521.

5. Beaugrand G, Brander K, Lindley J, Souissi S, Reid P: Plankton effect on cod recruitment in the North Sea. Nature 2003, 426:661-664.

6. Costanza R, d'Arge R, de Groot R, Farber S, Grasso M, Hannon B, Limburg K, Naeem S, O'Neill R, Paruelo J, et al: The Value of the World's Ecosystem Services and Natural Capital. Nature 1997, 387:253-260.

7. Frangoulis $C$, Christou $E$, Hecq J: Comparison of marine copepod outfluxes: Nature, rate, fate and role in the carbon and nitrogen cycles. Advances in Marine Biology 2005, 47:253-309.

8. Richardson A: In hot water: zooplankton and climate change. ICES Journal of Marine Science and Technology 2008, 65:279-295.

9. Venkateswaran K, Takai T, Navarro I, Nakano H, Hashimoto H, Siebeling R: Ecology of Vibrio cholerae non-O1 and Salmonella spp. and role of zooplankton in their seasonal distribution in Fukuyama coastal waters, Japan. Applied and Environmental Microbiology 1989, 55:1591-1598.

10. Asmat A, Usup G, Eds: The occurrence of aerolysin-positive Aeromonas hydrophila strains in seawater and associated with marine copepods. Resources 2002, 495-502, Proceedings of the Regional Symposium on Environment and Natural Resources.

11. Heidelberg J, Heidelberg K, Colwell R: Bacteria of the $\gamma$-subclass Proteobacteria associated with zooplankton in Chesapeake Bay. Applied and Environmental Microbiology 2002, 68:5498-5507.

12. Signoretto C, Burlacchini G, del Mar Lleò M, Pruzzo C, Zampini M, Pane L, Franzini G, Canepari P: Adhesion of Enterococcus faecalis in the nonculturable state to plankton Is the main mechanism responsible for persistence of this bacterium in both lake and seawater. Applied and Environmental Microbiology 2004, 70:6892-6896.

13. Bimi L: Potential vector species of Guinea worm (Dracunculus medinensis) in Northern Ghana. Vector Borne Zoonotic Diseases 2007, 7:324-329.

14. Dick T, Dixon B, Choudhury A: Diphyllobothrium, Anisakis and other fishborne parasitic zoonoses. Southeast Asian Journal of Tropical Medicine and Public Health 1991, 22:150-152.

15. Johnson S, Treasurer J, S B, Nagasawa K, Kabata Z: A review of the impact of parasitic copepods on marine aquaculture. Zoological Studies 2004, 43:229-243.

16. Piasecki W, Goodwin A, Eiras J, Nowak B: Importance of copepoda in freshwater aquaculture. Zoological Studies 2004, 43:193-205.

17. Costello M: The global economic cost of sea lice to the salmonid farming industry. Journal of Fish Diseases 2009, 32:115-118. 
18. Barreto F, Moy G, Burton R: Interpopulation patterns of divergence and selection across the transcriptome of the copepod Tigriopus californicus. Molecular Ecology 2011, 20:560-572.

19. Gregory TR, Ed: The Evolution of the Genome. San Diego: Elsevier; 2005.

20. Wyngaard G, Rasch E, Connelly B: Extraordinary augmentation of germline genome size in Cyclops kolensis (Crustacea, Copepoda): further evidence in support of a revised model of chromatin diminution. Chromosome Research 2011

21. Boxshall G, Halsey S: An Introduction to Copepod Diversity London: Ray Society; 2004.

22. Regier J, Shultz J, Zwick A, Hussey A, Ball B, Weter R, Martin J, Cunningham C: Arthropod relationships revealed by phylogenomic analysis of nuclear protein-coding sequences. Nature 2010, 463:1079-1083.

23. Andrew DR: A new view of insect-crustacean relationships II. Inferences from expressed sequence tags and comparisons with neural cladistics. Arthropod Structure \& Development 2011, 40:289-302.

24. Ho J: Why do symbiotic copepods matter? In Copepoda: Developments in Ecology, Biology and Systematics, Developments in Hydrobiology. Volume 156 Edited by: Lopes RM, Reid JW, Rocha CEF. Springer Netherlands; 2001:1-7.

25. Boxshall GA, Strong EE: An extraordinary shift in life habit within a genus of cyclopid copepods in Lake Tanganyika. Zoological Journal of the Linnean Society 2006, 146:275-285.

26. Dieterich C, Sommer RJ: How to become a parasite-lessons from the genomes of nematodes. Trends in Genetics 2009, 25:203-209.

27. Peacock CS, Seeger K, Harris D, Murphy L, Ruiz JC, Quail MA, Peters N, Adlem E, Tivey A, Aslett M, et al: Comparative genomic analysis of three Leishmania species that cause diverse human disease. Nature Genetics 2007, 39:839-847.

28. Tyagi S, Sharma M, Das A: Comparative genomic analysis of simple sequence repeats in three Plasmodium species. Parasitology Research 2011, 108:451-458

29. Ghedin E, Anton BP: Draft genome of the filarial nematode parasite Brugia malayi, (vol 317, pg 1756, 2007). Science 2009, 323:38-38,

30. Zimmer C: Parasite Rex New York: Simon \& Schuster; 2001.

31. Kurland CG, Collins LJ, Penny D: Genomics and the irreducible nature of eukaryote cells. Science 2006, 312:1011-1014.

32. Moran NA: Microbial minimalism: Genome reduction in bacterial pathogens. Cell 2002, 108:583-586.

33. Fast M, Johnson S, Eddy T, Pinto D, Ross N: Lepeophtheirus salmonis secretory/excretory products and their effects on Atlantic salmon immune gene regulation. Parasite Immunology 2007, 29:179-189.

34. Stock J: The Calvocheridae, a family of copepods inducing galls in seaurchin spines. Bijdragen tot de dierkunde 1968, 38:85-90.

35. Ribeiro JMC, Alarcon-Chaidez F, Francischetti IMB, Mans BJ, Mather TN Valenzuela JG, Wikel SK: An annotated catalog of salivary gland transcripts from Ixodes scapularis ticks. Insect Biochemistry and Molecular Biology 2006, 36:111-129.

36. Huys R, Llewellyn-Hughes J, Conroy-Dalton S, Olson P, Spinks J, Johnston D: Extraordinary host switching in siphonostomatoid copepods and the demise of the Monstrilloida: integrating molecular data, ontogeny and antennulary morphology. Molecular Phylogenetics and Evolution 2007, 43:368-378.

37. Mayer WE, Schuster LN, Bartelmes G, Dieterich C, Sommer RJ: Horizontal gene transfer of microbial cellulases into nematode genomes is associated with functional assimilation and gene turnover. Bmc Evolutionary Biology 2011, 11.

38. Tyler B, Tripathy S, Zhang $X$, Dehal $P$, Jiang $R$, Aerts A, Arredondo F, Baxter L, Bensasson D, Beynon J, et al: Phytophthora genome sequences uncover evolutionary origins and mechanisms of pathogenesis. Science 2006, 313:1261-1266

39. Fallang A, Denholm I, Horsberg T, Williamson M: A novel point mutation in the sodium channel gene of pyrethroid-resistant sea lice, Lepeophtheirus salmonis, (Crustacea: Copepoda). Diseases of Aquatic Organisms 2005, 65:129-136.

40. Campbell E, Pert C, Bowman A: RNA-interference methods for geneknockdown in the sea louse, Lepeophtheirus salmonis: studies on a putative prostaglandin E synthase. Parasitology 2009, 136:867-874.

41. Kircher M, Kelso J: High-throughput DNA sequencing-concepts and limitations. BioEssays news and reviews in molecular cellular and developmental biology John Wiley \& Son 2010, 32:524-536
42. Pimentel D, Zuniga R, Morrison D: Update on the environmental and economic costs associated with alien-invasive species in the United States. Ecological Economics 2005, 52:273-288.

43. Lee C: Evolutionary genetics of invasive species. Trends in Ecology and Evolution 2002, 17:386-391.

44. Geller J, Darling J, Carlton J: Genetic perspectives on marine biologica invasions. Annual Review of Marine Science 2010, 2:367-393.

45. Lee CE: Evolution of invasive populations. In The Encyclopedia of Biological Invasions. Edited by: Simberloff D, Rejmánek M. University of California Press; 2010:

46. Chu KH, Tam PF, Fung $\mathrm{CH}$, Chen QC: A biological survey of ballast water in container ships entering Hong Kong. Hydrobiologia 1997, 352:201-206.

47. Lee CE: Rapid and repeated invasions of freshwater by the saltwater copepod Eurytemora affinis. Evolution 1999, 53:1423-1434.

48. Lee CE, Remfert JL, Gelembiuk GW: Evolution of physiological tolerance and performance during freshwater invasions. Integrative and Comparative Biology 2003, 43:439-449.

49. Lee CE, Remfert JL, Chang Y-M: Response to selection and evolvability of invasive populations. Genetica 2007, 129:179-192.

50. Lee CE, Kiergaard M, Eads BD, Gelembiuk GW, Posavi M: Pumping ions: Rapid parallel evolution of ionic regulation following habitat invasions. Evolution 2011, 65:2229-2244.

51. Wang X, Sun Q, McGrath SD, Mardis ER, Soloway PD, Clark AG: Transcriptome-Wide Identification of Novel Imprinted Genes in Neonatal Mouse Brain. Plos One 2008, 3.

52. Wittkopp PJ, Haerum BK, Clark AG: Evolutionary changes in cis and trans gene regulation. Nature 2004, 430:85-88.

53. Hairston N, Van Brunt R, Kearns C, Engstrom D: Age and survivorship of diapausing eggs in a sediment egg bank. Ecology 1995, 76:1706-1711.

54. Kerfoot W, Weider L: Experimental paleoecology (resurrection ecology): Chasing Van Valen's red queen hypothesis. Limnology and Oceanography 2004, 49:1300-1316.

55. Weider L, Lampert W, Wessels M, Colbourne J, Limburg P: Long-term genetic shifts in a microcrustacean egg bank associated with anthropogenic changes in the Lake Constance ecosystem. Proceedings of the Royal Society of London Series B-Biological Sciences 1997, 264:1613-1618.

56. Decaestecker E, Gaba S, Raeymaekers J, Stoks R, Van Kerckhoven L, Ebert D, De Meester L: Host-parasite Red Queen dynamics archived in pond sediment. Nature 2007, 450:870-873.

57. Williams-Howze J: Dormancy in the free-living copepod orders Cyclopoida, Calanoida, Harpacticoida. Oceanography and Marine Biology; an Annual Review 1997, 35:257-321.

58. Feder ME, Mitchell-Olds T: Evolutionary and ecological functional genomics. Nature Reviews Genetics 2003, 4:651-657.

59. Chen T, Amons R, Clegg JS, Warner AH, MacRae TH: Molecular characterization of artemin and ferritin from Artemia franciscana. European Journal of Biochemistry 2003, 270:137-145.

60. Rinehart JP, Robich RM, Denlinger DL: Isolation of diapause-regulated genes from the flesh fly, Sarcophaga crassipalpis by suppressive subtractive hybridization. Journal of Insect Physiology 2010, 56:603-609.

61. Zhang Q, Denlinger DL: Molecular characterization of heat shock protein 90,70 and 70 cognate cDNAs and their expression patterns during thermal stress and pupal diapause in the corn earworm. Journal of Insect Physiology 2010, 56:138-150.

62. Tarrant A, Baumgartner M, Verslycke T, Johnson C: Differential gene expression in diapausing and active Calanus finmarchicus. Marine Ecology Progress Series 2008, 355:193-207.

63. Cushing D: Plankton production and year-class strength in fish populations: an update of the match/mismatch hypothesis. In Advances in Marine Biology. Edited by: Blaxter JHS, Southward AJ. San Diego, CA; 1990:250-313.

64. Parfrey LW, Lahr DJG, Katz LA: The dynamic nature of eukaryotic genomes. Molecular Biology and Evolution 2008, 25:787-794.

65. Rasch EM, Wyngaard GA, Connelly BA: Heterochromatin endoreduplication prior to gametogenesis and chromatin diminution during early embryogenesis in Mesocyclops edax (Copepoda: crustacea). Journal of Morphology 2008, 269:387-397.

66. Drouin G: Chromatin diminution in the copepod Mesocylcops edax: diminution of tandemly repeated DNA families from somatic cells. Genome 2006, 49:657-665. 
67. Zagoskin M, Grishanin A, Korolev A, Palenko M, Mukha D: Characterization of Cyclops kolensis inter-simple sequence repeats in germline and postdiminution somatic cells. Doklady Biochemistry and Biophysics 2008, 423:337-341.

68. Rasch EM, Wyngaard GA: Evidence for endoreduplication: Germ cell DNA levels prior to chromatin diminution in Mesocyclops edax. Journal of Histochemistry \& Cytochemistry 2001, 49:795-796.

69. Lynch M: The Origins of Genome Architecture Massachussetts, Sunderland: Sinauer Associates; 2007.

70. Burt A, Trivers T: Genes in Conflict: The Biology of Selfish Genetic Elements Belknap Press; 2008.

71. Rautian MS: Molecular Genome Organization in Ciliates. Russian Journal of Genetics 2010, 46:1058-1061.

72. Kloc M, Zagrodzinska B: Chromatin elimination-an oddity or a common mechanism in differentiation and development? Differentiation 2001, 68:84-91.

73. Machida RJ, Miya MU, Nishida M, Nishida S: Complete mitochondrial DNA sequence of Tigriopus japonicus (Crustacea: Copepoda). Marine Biotechnology 2002, 4:406-417.

74. Ki J-S, Park HG, Lee J-S: The complete mitochondrial genome of the cyclopoid copepod Paracyclopina nana: A highly divergent genome with novel gene order and atypical gene numbers. Gene 2009, 435:13-22.

75. Minxiao W, Song S, Chaolun L, Xin S: Distinctive mitochondrial genome of Calanoid copepod Calanus sinicus with multiple large non-coding regions and reshuffled gene order: Useful molecular markers for phylogenetic and population studies. BMC Genomics 2011, 12:20pp.

76. Burton R, Byrne R, PD R: Three divergent mitochondrial genomes from California populations of the copepod Tigriopus californicus. Gene 2007, 402:53-59.

77. Rand DM, Haney RA, Fry AJ: Cytonuclear coevolution: the genomics of cooperation. Trends in Ecology \& Evolution 2004, 19:645-653.

78. Ellison C, Burton R: Cytonuclear conflict in interpopulation hybrids: the role of RNA polymerase in mtDNA transcription and replication. Journal of Evolutionary Biology 2010, 23:528-538.

79. Edmands S, Northrup S, Hwang A: Maladapted gene complexes within populations of the intertidal copepod Tigriopus californicus. Evolution 2009, 63:2184-2192.

80. Pritchard VL, Dimond L, Harrison JS, Velazquez CCS, Zieba JT, Burton RS, Edmands S: Interpopulation hybridization results in widespread viability selection across the genome in Tigriopus californicus. BMC Genetics 2011, 12.

81. Colbourne JK, Pfrender ME, Gilbert D, Thomas WK, Tucker A, Oakley TH, Tokishita S, Aerts A, Arnold GJ, Basu MK, et al: The Ecoresponsive Genome of Daphnia pulex. Science 2011, 331:555-561.

82. Lampert W: Daphnia: Development of a model organism in ecology and evolution. In Excellence in Ecology. Volume 21. Edited by: Kinne O. Oldendorf/Luhe: International Ecology Institute; 2011:250.

83. Rhee J, Raisuddin S, Lee K, Seo J, Ki J, Kim I, Park H, Lee J: Heat shock protein ( $\mathrm{Hsp}$ ) gene responses of the intertidal copepod Tigriopus japonicus to environmental toxicants. Comparative Biochemistry and Physiology Part C, Toxicology and Pharmacology 2009, 149:104-112.

84. Hansen B, Nordtug T, Altin D, Booth A, Hessen K, Olsen A: Gene expression of GST and CYP330A1 in lipid-rich and lipid poor female Calanus finmarchicus (Copepoda: Crustacea) exposed to dispersed oil. Journal of Toxicology and Environmental Health 2009, 71:131-136.

85. Ki J, Raisuddin S, Lee K, Hwang D, Han J, Rhee J, Kim I, Park H, Ryu J, Lee J: Gene expression profiling of copper-induced responses in the intertidal copepod Tigriopus japonicus using a $6 \mathrm{~K}$ oligochip microarray. Aquatic Toxicology 2009, 93:177-187.

86. Hansen B, Dag A, Booth A, Vang S-H, Frenzel M, Sorheim K, Brakstad O, Størset T: Molecular effects of diethanolamine exposure on Calanus finmarchicus (Crustacea: Copepoda). Aquatic Toxicology 2010.

87. Voznesensky M, Lenz P, Spanings-Pierrot C, Towle D: Genomic approaches to detecting thermal stress in Calanus finmarchicus (Copepoda: Calanoida). Journal of Experimental Marine Biology and Ecology 2004, 311:37-46.

88. Christie A, Lenz P, Hassett R, Smith C, Batta LP, Ünal E, A B, Towle D: Calanus finmarchicus cDNA library: a genomic tool for studies of zooplankton physiological ecology. Mount Desert Island Biological Lab Bulletin 2009, 48:112-113.
89. Bucklin A, Hopcroft R, Kosobokova K, Nigro L, Ortman B, Jennings R, Sweetman C: DNA barcoding of Arctic Ocean holozooplankton for species identification and recognition. Deep-Sea Research Part II: Topical Studies in Oceanography 2009, 57:40-48.

90. Burton R: Molecular markers, natural history, and conservation of marine animals. Bioscience 2009, 59:831-840.

91. Machida R, Hashiguchi Y, Nishida M, Nishida S: Zooplankton diversity analysis through single-gene sequencing of a community sample. BMC Genomics 2009, 10:438.

92. Kirchman D: Mysteries of Metagenomics revealed. Limnology and Oceanography Bulletin 2010, 18:2-6.

93. Hugenholtz P, Tyson G: The nuts and bolts of metagenomics. Nature 2008, 455:481-483

94. Stoeck T, Bass D, Nebel M, Christen R, Jones M, Breiner H-W, Richards T: Multiple marker parallel tag environmental DNA sequencing reveals a highly complex eukaryotic community in marine anoxic water. Molecular Ecology 2010, 19(Suppl. 1):21-31.

95. McBeath A, Penston M, Snow M, Cook P, Bricknell I, Cunningham C: Development and application of real-time PCR for specific detection of Lepeophtheirus salmonis and Caligus elongatus larvae in Scottish plankton samples. Diseases of Aquatic Organisms 2006, 73:141-150.

96. Eichner C, Frost P, Dysvik B, Kristiansen B, Jonassen I, Nilsen F: Salmon louse (Lepeophtheirus salmonis) transcriptomes during post molting maturation and egg production, revealed using EST-sequencing and microarray analysis. BMC Genomics 2008, 9:126.

97. Skern-Mauritzen R, Frost P, Dalvin SK, Sommerset I, Nilsen F: A trypsin-like protease with apparent dual function in early Lepeophtheirus salmonis (Kroyer) development. BMC Molecular Biology 2009, 10:44.

98. Ashburner $\mathrm{M}$, Bergman CM: Drosophila melanogaster: A case study of a model genomic sequence and its consequences. Genome Research 2005, 15:1661-1667.

99. Celniker SE, Dillon LAL, Gerstein MB, Gunsalus KC, Henikoff S, Karpen GH, Kellis M, Lai EC, Lieb JD, MacAlpine DM, et al: Unlocking the secrets of the genome. Nature 2009, 459:927-930.

100. Land KM: The mosquito genome: perspectives and possibilities. Trends in Parasitology 2003, 19:103-105.

101. Robinson GE, Evans JD, Maleszka R, Robertson HM, Weaver DB, Worley K, Gibbs RA, Weinstock GM: Sweetness and light: illuminating the honey bee genome. Insect Molecular Biology 2006, 15:535-539.

102. Burton RS, Byrne RJ, Rawson PD: Three divergent mitochondrial genomes from California populations of the copepod Tigriopus californicus. Gene 2007, 403:53-59.

103. Pennisi E: Using DNA to Reveal a Mosquito's History. Science 2011, 331:1006-1007.

104. Bergsoe V: Philichthys xiphiae Stp. monographisk fremstillet Kjøbenhavn: W. Prior; 1864.

105. Haeckel E: Kunstformen der Natur Leipzig and Vienna: Verlag des Bibliographischen Instituts; 1899.

106. Giesbrecht W: Systematik und Faunistik der Pelagischen Copepoden des Golfes von Neapel und der Angrenzenden Meeres-Abschnitte Berlin: Verlag Von R. Friedlander \& Sohn; 1892.

107. Scott T, Scott A: The British parasitic Copepoda London: Ray Society; 1913.

108. Jurine L: Histoire des monocles qui se trouvent aux environs de Genève Paris: J. J. Paschoud; 1820

doi:10.1186/1742-9994-8-22

Cite this article as: Bron et al.: Observing copepods through a genomic lens. Frontiers in Zoology 2011 8:22. 